\title{
A preliminary investigation of radar rainfall estimation in the Ardennes region and a first hydrological application for the Ourthe catchment
}

\author{
A. Berne ${ }^{1}$, M. ten Heggeler ${ }^{1}$, R. Uijlenhoet ${ }^{1}$, L. Delobbe ${ }^{2}$, Ph. Dierickx ${ }^{3}$, and M. de Wit ${ }^{4}$ \\ ${ }^{1}$ Wageningen University, Environmental Sciences Group, Chair of Hydrology and Quantitative Water Management, The \\ Netherlands \\ ${ }^{2}$ Royal Meteorological Institute, Brussels, Belgium \\ ${ }^{3}$ Ministère de l'Équipement et des Transports, Service d'Études Hydrologiques, Namur, Belgium \\ ${ }^{4}$ Ministry of Transport, Public Works and Water Management, Institute for Inland Water Management and Waste Water \\ Treatment (RIZA), Arnhem, The Netherlands
}

Received: 12 October 2004 - Revised: 20 January 2005 - Accepted: 2 February 2005 - Published: 4 March 2005

\begin{abstract}
This paper presents a first assessment of the hydrometeorological potential of a C-band doppler weather radar recently installed by the Royal Meteorological Institute of Belgium near the village of Wideumont in the southern Ardennes region. An analysis of the vertical profile of reflectivity for two contrasting rainfall events confirms the expected differences between stratiform and convective precipitation. The mean areal rainfall over the Ourthe catchment upstream of Tabreux estimated from the Wideumont weather radar using the standard Marshall-Palmer reflectivity-rain rate relation shows biases between $+128 \%$ and $-42 \%$ for six selected precipitation events. For two rainfall events the radar-estimated mean areal rainfall is applied to the gaugecalibrated (lumped) HBV-model for the Ourthe upstream of Tabreux, resulting in a significant underestimation with respect to the observed discharge for one event and a closer match for another. A bootstrap analysis using the radar data reveals that the uncertainty in the hourly discharge from the $\sim 1600 \mathrm{~km}^{2}$ catchment associated with the sampling uncertainty of the mean areal rainfall estimated from 10 rain gauges evenly spread over the catchment amounts to $\pm 25 \%$ for the two events analyzed. This uncertainty is shown to be of the same order of magnitude as that associated with the model variables describing the initial state of the model.
\end{abstract}

\section{Introduction}

The Ardennes, an undulating area of moderate relief (maximum elevation $\sim 700 \mathrm{~m}$ ), is an important natural laboratory to study the hydrometeorology of mountainous catchments.

Correspondence to: R. Uijlenhoet

(remko.uijlenhoet@wur.nl)
The western part of the Ardennes (France, Belgium, Netherlands) mainly drains to the river Meuse, whereas the eastern part of the region (Luxemburg, Germany) mainly drains to the river Rhine (via the Mosel). Both the Meuse (e.g. Berger, 1992) and the Rhine (e.g. Kwadijk, 1993) fulfill important functions in the water supply of The Netherlands. These rivers supply water for domestic, industrial and agricultural use and also fulfill important navigational, ecological and recreational functions. It is therefore of significant societal relevance to develop strategies to mitigate the impact of floods and droughts associated with the discharge regimes of the rivers Meuse and Rhine. To achieve this objective, the hydrometeorology of the (mostly mountainous) upstream areas, such as the Ardennes, needs to be better understood.

Hydrologists have traditionally paid much more attention to the development of more sophisticated rainfall-runoff modeling approaches than to the development of improved techniques for the measurement and prediction of the spacetime variability of precipitation. This is to be deplored, since rainfall is the driving source of water behind most terrestrial hydrological processes. All previous hydrological modeling efforts in the Ardennes have relied on lumped or (semi-)distributed rainfall-runoff models with conceptual representations of the relevant hydrological processes (infiltration, surface runoff, changes in soil moisture storage, groundwater recharge, etc.) in combination with rainfall input obtained from networks of raingauges (e.g. Velner, 2000; Groot Zwaaftink, 2003). The aim of a recently established research collaboration between Wageningen University (WU), the Royal Meteorological Institute of Belgium (RMI) and the Hydrological Service of the Walloon Region of Belgium (MET-SETHY) is to investigate whether an improved assessment of the space-time structure of precipitation, as can be obtained with a newly installed weather radar 
Table 1. Some characteristics of the Wideumont weather radar.

\begin{tabular}{ll}
\hline Property & Value \\
\hline Location & Wideumont, Luxembourg Province, Walloon Region, Belgium \\
Operational since & October 2001 \\
Type of radar & Gematronik pulse doppler \\
Frequency/wavelength & C-band $(5.64 \mathrm{GHz} / 5.32 \mathrm{~cm})$ \\
Mean transmit power & $250 \mathrm{~W}$ \\
Height of tower base & $535 \mathrm{~m}$ \\
Height of tower & $50 \mathrm{~m}$ \\
Height of antenna & $585 \mathrm{~m}$ \\
Antenna diameter & $4.2 \mathrm{~m}$ \\
Radome diameter & $6.7 \mathrm{~m}$ \\
Elevations & $0.5^{\circ}, 1.2^{\circ}, 1.9^{\circ}, 2.6^{\circ}, 3.3^{\circ}, 4.0^{\circ}, 4.9^{\circ}, 6.5^{\circ}, 9.4^{\circ}, 17.5^{\circ}$ \\
Maximum range reflectivity processing & $240 \mathrm{~km}$ \\
Maximum range doppler processing & $120 \mathrm{~km}$ \\
Typical range resolution & $0.5 \mathrm{~km}$ \\
Time interval precipitation products* & $5 \mathrm{~min}$. \\
Time interval volume reflectivity scans & $15 \mathrm{~min}$. \\
Time interval doppler scans & $15 \mathrm{~min}$. \\
\hline
\end{tabular}

* The Wideumont radar performs a 5-elevation scan every $5 \mathrm{~min}$, from which the precipitation products are derived. The doppler and full volume scans are performed alternatively every $15 \mathrm{~min}$.

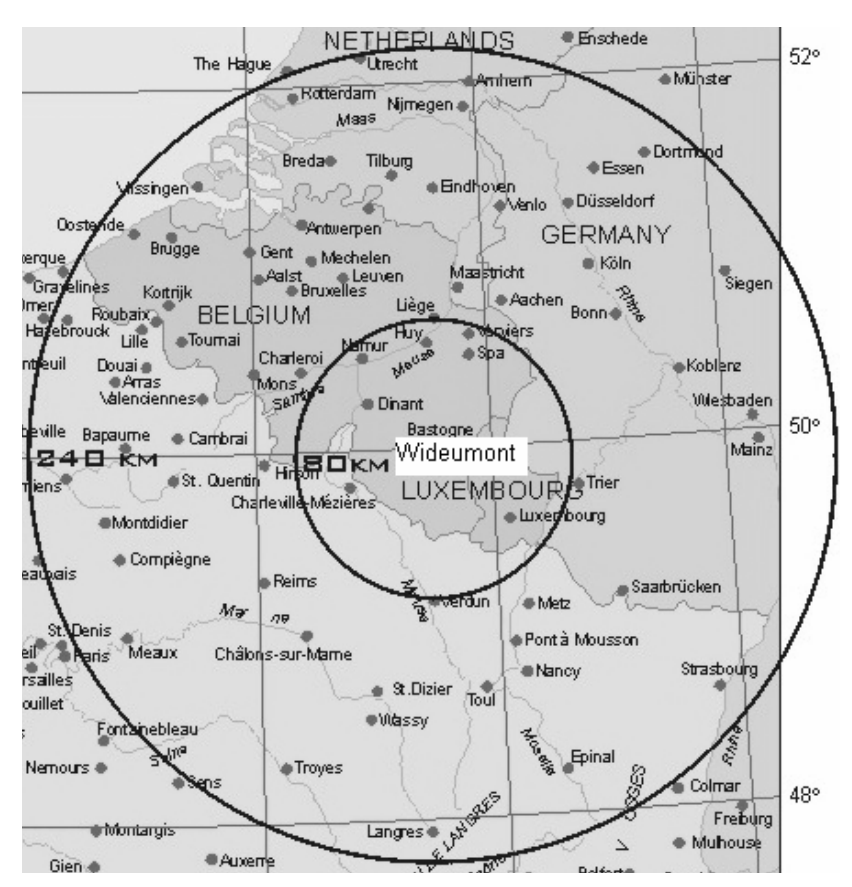

Fig. 1. Location of the RMI C-band doppler weather radar in the southern Ardennes. The circles represent 80 and $240 \mathrm{~km}$ range markers. The area of interest (Ourthe catchment upstream of Tabreux, see Fig. 4) is located entirely inside the inner circle (source: RMI).

in the Ardennes (RMI, 2001), in combination with an innovative approach towards modeling the rainfall-runoff process, will lead to an improved understanding of the hydrometeorology of Ardennes catchments.
An improved knowledge of the hydrometeorology of the mountainous Ardennes catchments will ultimately lead to improved real-time flood forecasts, in particular for the rivers Meuse and Mosel (hence the Rhine). It is also relevant for achieving improved process representations (and therefore improved assimilation) of land surface hydrology in numerical weather prediction models and climate models (e.g. Van den Hurk et al., 2001). Global climate change may affect the hydrological behavior of rivers and streams and consequently the availability of water for a variety of purposes, as identified above (Brandsma, 1995). The possible impacts of global climatic change on the discharge regime of the river systems of the Meuse and the Rhine have been studied extensively during recent years (Kwadijk, 1993; Pfister et al., 2000; Wójcik and Buishand, 2003; Uijlenhoet et al., 2001; De Wit et al., 2001). However, all of these studies have been based on simplified representations of the space-time precipitation fields as obtained from networks of raingauges and conceptual representations of the relevant hydrological processes where individual catchments are subdivided into arbitrary grid squares. This paper presents a first assessment of the hydrometeorological potential of a recently installed weather radar in the Ardennes.

\section{The RMI weather radar near Wideumont}

The Royal Meteorological Institute of Belgium (RMI) recently installed a new Gematronik C-band doppler weather radar near the village of Wideumont $(535 \mathrm{~m})$, in the southern Ardennes (Province of Luxembourg), close to the border with the Grand Duchy of Luxembourg (RMI, 2001). This is in fact the first and only weather radar covering nearly the 


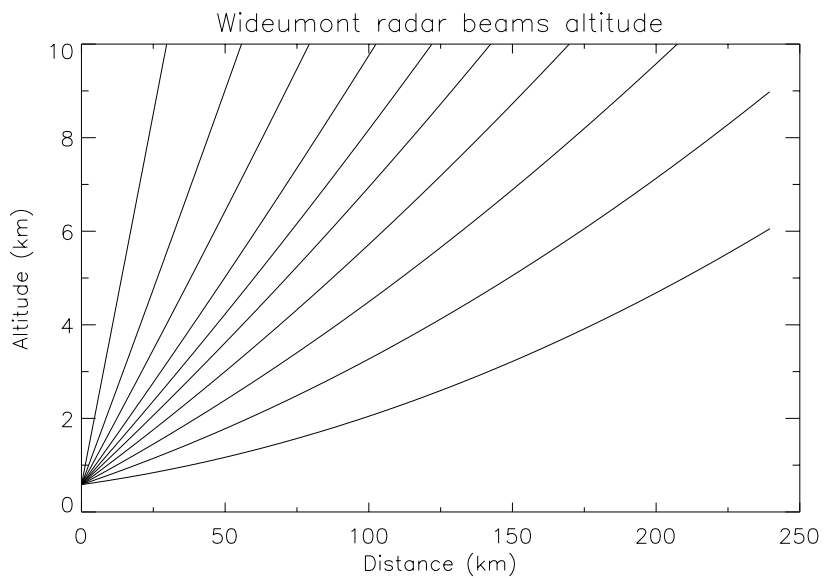

Fig. 2. Height $(\mathrm{km})$ of the radar beam axis above mean sea level as a function of range from the radar $(\mathrm{km})$ for each of the 10 elevation angles of the Wideumont weather radar volume reflectivity scan (assuming normal propagation through a standard atmosphere).

entire Ardennes area and at the same time the first weather radar owned and operated by the RMI. The mean transmit power of the radar amounts $250 \mathrm{~W}$, it has a $4.2 \mathrm{~m}$ diameter parabolic antenna (covered by a radome) and is installed on a $50 \mathrm{~m}$ high tower. The radar performs every $15 \mathrm{~min}$. a 10 elevation volume scan of the 3D structure of the rainfall field out to a distance of $240 \mathrm{~km}$ and similarly a doppler scan to a range of $120 \mathrm{~km}$. Figure 1 shows the location and coverage of the weather radar and Table 1 provides some relevant characteristics.

Figure 2 shows the dependence of the height of the radar beam axis as a function of the distance from the radar ("range") for each of the 10 elevation angles which constitute a complete volume reflectivity scan of the Wideumont weather radar $\left(0.5^{\circ}, 1.2^{\circ}, 1.9^{\circ}, 2.6^{\circ}, 3.3^{\circ}, 4.0^{\circ}, 4.9^{\circ}, 6.5^{\circ}\right.$, $9.4^{\circ}$, and $17.5^{\circ}$, respectively). The exact dependence is determined both by the curvature of the earth and by the amount of refraction the radar beam is experiencing. Figure 2 is based on the assumption of normal propagation through a standard atmosphere. It is our ambition to employ and expand existing methods for the processing of radar data (e.g. SanchezDiezma et al., 2001) and apply it to the volume scan reflectivity data from the new weather radar. This will lead to an operational correction procedure for known error sources relevant to radar rainfall estimation, such as the adverse effects of attenuation, the vertical profile of reflectivity and ground clutter (Andrieu et al., 1997; Creutin et al., 1997).

Due to the moderate rainfall intensities which are to be expected in this region from a climatological perspective, attenuation of the radar signal due to rainfall present on the path between the radar antenna and the region of interest is likely going to be less of a problem than for instance in Mediterranean areas (e.g. Corral et al., 2000). On the other hand, operational C-band weather radars such as the Wideumont radar are known to be prone to attenuation even at moderate rain rates (as compared to $\mathrm{S}$-band radars which are vir-
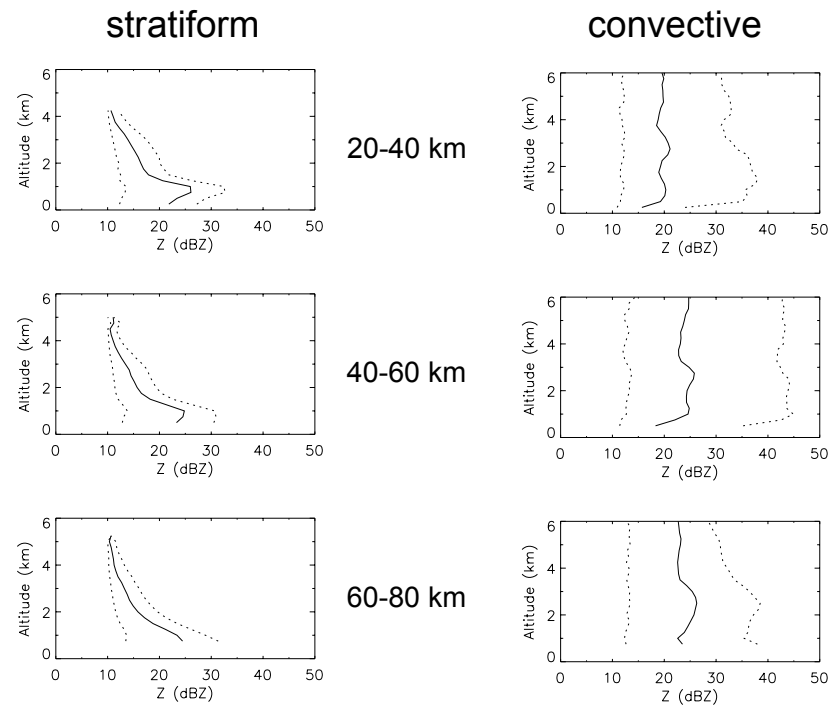

$60-80 \mathrm{~km}$
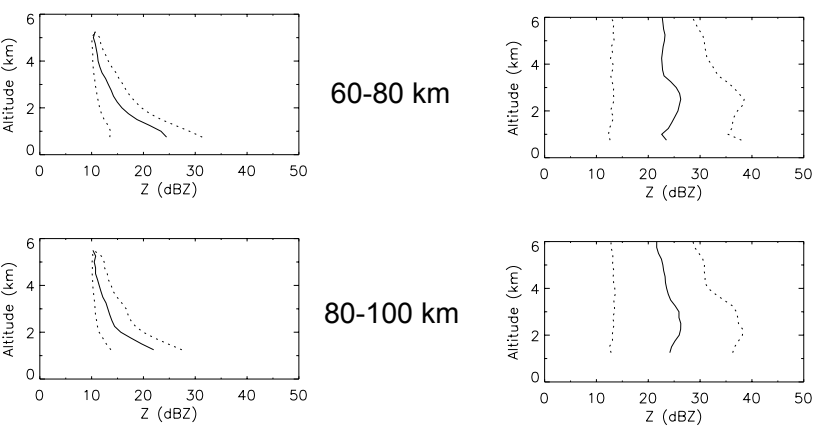

$80-100 \mathrm{~km}$

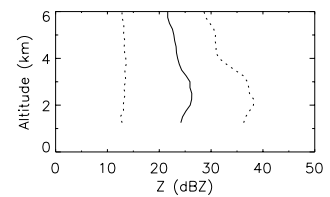

Fig. 3. Mean vertical reflectivity profiles (bold lines) and $20 \%-$ $80 \%$ quantiles (dashed lines) for four different $20 \mathrm{~km}$ range intervals at increasing distances from the Wideumont weather radar. Left panel: typical stratiform event (1 March 2003). Right panel: typical convective event (19 August 2002).

tually insensitive to rain-induced attenuation). In addition, the attenuation caused by rain water present on the radome (the protective dome covering the radar antenna) during and shortly after rainfall events has been shown to pose a serious problem (e.g. Germann, 1999). Therefore, the development of accurate and robust attenuation correction procedures is still the topic of ongoing research. Berne and Uijlenhoet (2004) present a theoretical study to quantify the effects of attenuation on radar-rainfall estimation and to assess the performance of different attenuation compensation schemes in a stochastic framework.

The significant height of the radar antenna (close to $600 \mathrm{~m}$ ) is also expected to produce appreciable bright band effects, particularly in the winter half year, which makes a correction for the vertical profile of reflectivity of prime importance (see Sect. 3.1). Similarly, in mountainous areas such as the Ardennes, ground clutter as a result of interception of the radar beam by surrounding relief will generally be a major concern, even though the Wideumont radar is located on one of the highest hills in the region. Procedures to correct for these error sources exist in principle and have shown their effectiveness in other areas (southern France, Catalunya). It will be a challenge to investigate their reliability in the Ardennes. Ultimately, application of these correction procedures to the data collected with the new weather radar will lead to reliable maps of the spatially varying rainfall field at a $1 \mathrm{~km}$ resolution and a 5 min time step. 
Table 2. Characteristic precipitation events selected by the RMI, the corresponding total mean areal rainfall accumulations over the Ourthe catchment upstream of Tabreux as derived from radar and raingauges, and the resulting bias of the radar rainfall estimates with respect to the gauge estimates (note that on 30 July 2002 the radar stopped functioning at 19:20 UTC, when most thunderstorms had passed but it was still raining over the Ourthe catchment).

\begin{tabular}{ccccc}
\hline Date & Type of event & Radar $(\mathrm{mm})$ & Gauges $(\mathrm{mm})$ & Bias $(\%)$ \\
\hline 4 May 2002 & convective & 19.1 & 32.7 & -42 \\
30 July 2002 & convective & 10.2 & 9.8 & +4 \\
19 August 2002 & convective & 7.3 & 3.2 & +128 \\
24 November 2002 & stratiform & 9.1 & 7.6 & +20 \\
30 January 2003 & stratiform & 4.2 & 2.4 & +75 \\
1 March 2003 & stratiform & 9.1 & 10.3 & -12 \\
\hline
\end{tabular}

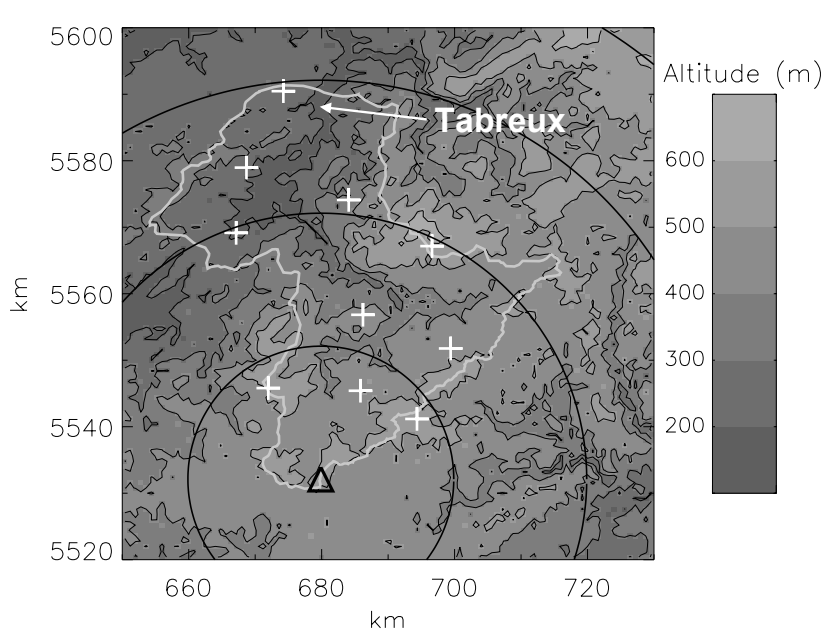

Fig. 4. Ourthe catchment upstream of Tabreux $\left(1597 \mathrm{~km}^{2}\right)$ with the location of the 10 MET-SETHY rain gauges and the Wideumont $\operatorname{radar}(\Delta)$. The black circles indicate the distance to the radar, with an increment of $20 \mathrm{~km}$.

\section{Results and discussion}

\subsection{Analysis of the vertical structure of precipitation}

The first radar data set that was analyzed in the framework of the collaboration between WU and RMI consisted of volume scan radar reflectivity data for a selection of six contrasting precipitation events (Table 2) which the RMI considered characteristic for the first two years since the Wideumont weather radar became operational (2001-2003). The employed volume scans consist of 10 elevations and were collected every $15 \mathrm{~min}$ (Table 1 ). Figure 3 presents an analysis of those data in terms of the range dependence of the so-called vertical profile of reflectivity (VPR), an important source of error when it comes to radar-rainfall estimation (Andrieu et al., 1997; Creutin et al., 1997). The figure shows that, as would be expected, events which can be defined as "stratiform" (such as 1 March 2003) are characterized by vertical profiles of reflectivity with a pronounced maximum just below the zero degree isotherm (the so-called radar bright band), which seems to gradually disappear at longer ranges due to the increased height and averaging volume of the radar at those ranges (see Fig. 2). The bright band is caused by an increased reflectivity from relatively large melting precipitation particles with a frozen interior and a liquid exterior. The "convective" events (such as 19 August 2002) do not display such a feature and exhibit much more uniform vertical reflectivity profiles. The smoothing of the profiles at longer ranges and the loss of information at low elevations remain apparent, however. This demonstrates the importance of accurate and robust VPR correction procedures for radar rainfall estimation, particularly at longer ranges.

Figure 3 shows both the mean vertical reflectivity profiles and the $20 \%$ and $80 \%$ quantiles for 4 different $20 \mathrm{~km}$ range intervals at increasing distances from the Wideumont weather radar. The quantiles provide a measure of the spatial and temporal variability of the retrieved vertical profiles. Clearly, the variability associated with the convective event is much stronger than that associated with the stratiform event. This confirms the well-established fact that stratiform precipitation is characterized by a pronounced variability in the vertical direction and a more homogeneous appearance in the horizontal direction (i.e. a stratified or layered structure), whereas the opposite is true for convective precipitation. These properties also form the basis of stratiformconvective separation techniques that have been proposed in the literature (e.g. Steiner et al., 1995; Sanchez-Diezma et al., 2000). Further research on this topic will ultimately contribute to the development of an operational VPR identification and correction algorithm, which has a high priority for the RMI. The smoothing of the profiles at longer ranges and the loss of information at low elevations mentioned earlier show that it will be a particular challenge to develop accurate and robust "local" VPR correction procedures based on volume reflectivity scan data from the Wideumont weather radar.

3.2 Hydrological application of radar rainfall estimates for the Ourthe basin

To perform a first assessment of the hydrological potential of the Wideumont weather radar, the Ourthe catchment up- 


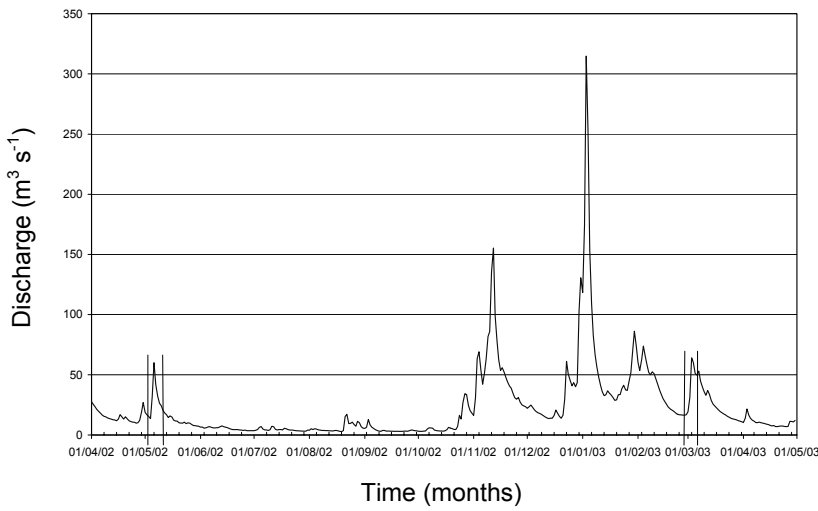

Fig. 5. Daily averaged discharge from the upper Ourthe catchment at Tabreux for the period April 2002-May 2003. The vertical lines indicate the periods 4-10 May 2002 (left) and 1-7 March 2003 (right), which have been analyzed as part of the research project presented in this paper (source: MET-SETHY).

stream of Tabreux was selected as study area. Figure 4 shows the topography of the $1597 \mathrm{~km}^{2}$ catchment with the location of the 10 MET-SETHY rain gauges covering the area. Because the radar is located near the highest part of the catchment, radar beam blocking by the relief is limited. From the six events for which radar data were provided by the RMI, two were selected for their hydrological significance, namely the rainfall-runoff events of 4-10 May 2002 and 1-7 March 2003. It should be noted that both events are minor with respect to the flood peaks that occurred during the 2002-2003 winter season (Fig. 5), which will be studied as part of a future collaborative research project. MET-SETHY kindly provided hourly raingauge and discharge data for the Ourthe at Tabreux for these events. For the hydrological simulations the HBV-model (Lindström et al., 1997) was used. An HBVschematization for the Ourthe catchment has been calibrated (1969-1984) and validated (1985-1998) in a previous study by Groot Zwaaftink (2003).

The determination of the initial state of the model, i.e. the contents of the moisture reservoirs (Fig. 6) at the start of a simulation, is always a difficult issue when it comes to running a hydrological model on an event basis. The 30-year (1968-1998) HBV model run derived from Groot Zwaaftink (2003) was employed to choose "optimal" initial conditions for both selected events by searching in the database for analogous hydrographs during the month preceding the discharge events, employing the Nash-Sutcliffe parameter as an error criterion (Ten Heggeler, 2004).

3.2.1 Comparison of radar estimates with rain gauge measurements

The mean areal rainfall estimated from the second elevation of the Wideumont weather radar volume scan reflectivity data using the standard Marshall-Palmer reflectivity-rain rate relation (without adjustment to rain gauges) showed a $42 \%$ underestimation with respect to the gauge average rainfall

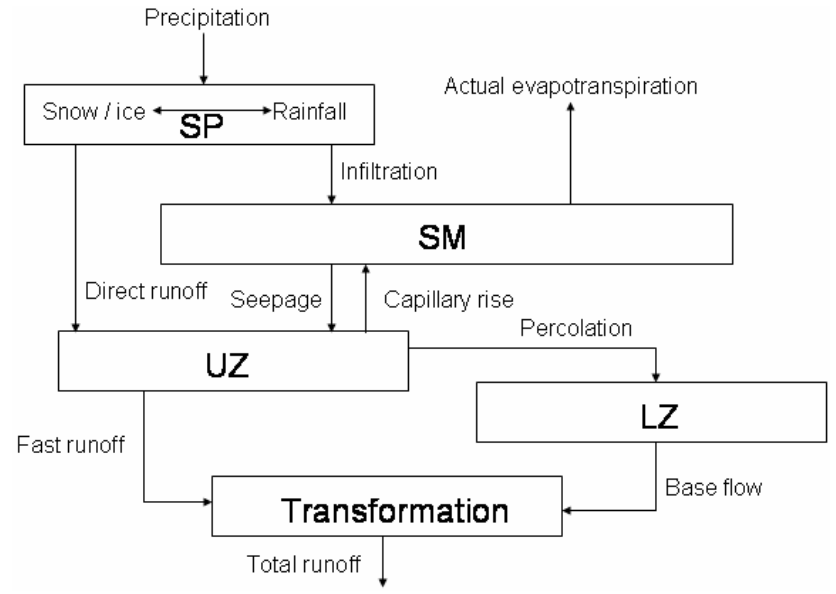

Fig. 6. The structure of the precipitation runoff model HBV (Lindström et al., 1997). Four reservoirs can be identified, the precipitation reservoir (SP), the soil moisture reservoir (SM), the fast runoff reservoir (UZ), and the base flow reservoir (LZ), respectively. The transformation routine transforms the fast runoff and base flow into the total runoff.

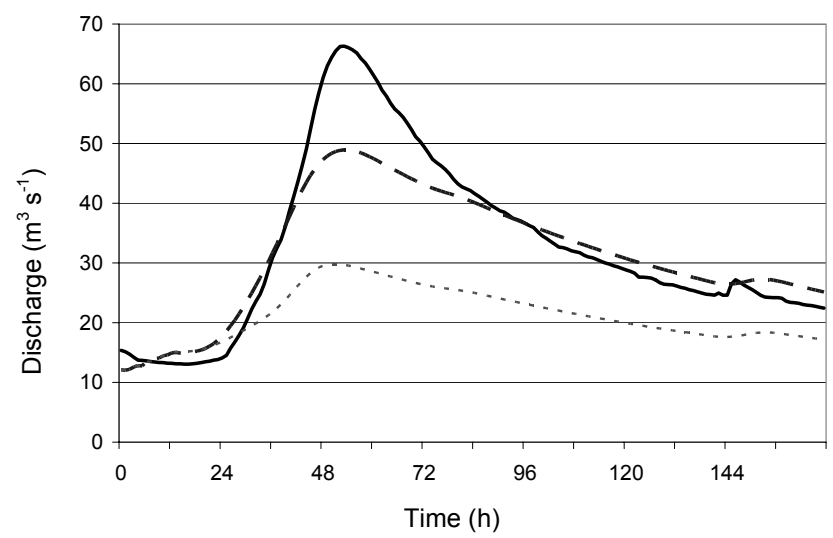

Fig. 7. Observed hourly discharge (solid line) at Tabreux for the period 4-10 May 2002 (source: MET-SETHY) and calculated discharge using the (lumped) HBV-model based on mean areal rainfall from rain gauge measurements (dashed line) and uncorrected radar measurements (dotted line).

for 4-5 May 2002 and a $12 \%$ underestimation for 1 March 2003 (the stratiform event of Fig. 3). Table 2 lists the biases associated with the other four selected precipitation events as well. The second rather than the first elevation was employed to minimize the possible adverse effects of ground clutter. It is the subject of ongoing research whether the underestimation for 4-5 May 2002 may be attributed to an erroneous reflectivity-rain rate relation and/or to rain-induced attenuation.

\subsubsection{Hydrological application}

Although the temporal dynamics is correctly reproduced, the application of the radar-estimated mean areal rainfall to the gauge-calibrated HBV-model for the Ourthe upstream of 
Table 3. Mean values of the ratio between the $20 \%$ and $80 \%$ quantiles and the "true" mean areal rainfall $\left(R_{20} /<R>\right.$ and $\left.R_{80} /<R>\right)$ for the two studied events.

\begin{tabular}{ccc}
\hline & $R_{20} /<R>$ & $R_{80} /<R>$ \\
\hline 4-5 May 2002 & 0.66 & 1.31 \\
1 March 2003 & 0.76 & 1.22 \\
\hline
\end{tabular}
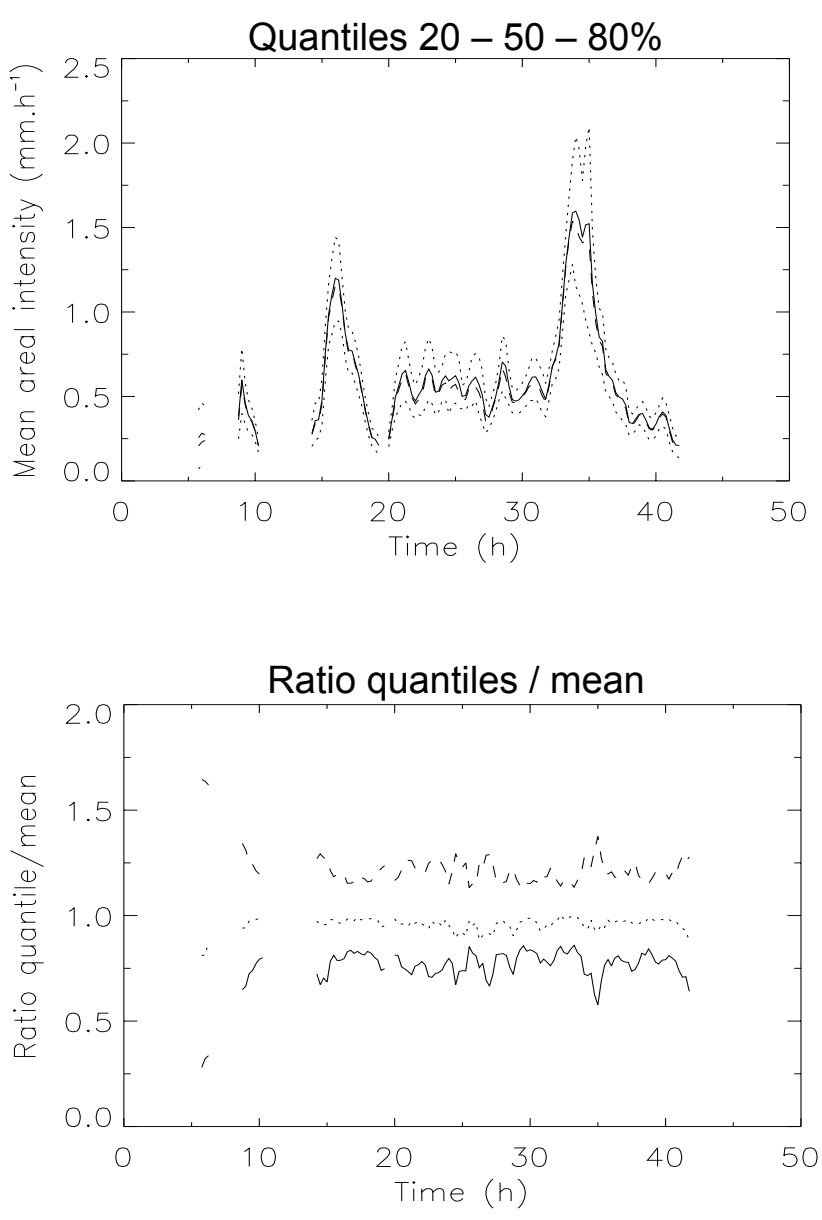

Fig. 8. Top panel: $20 \%$ (dotted line), $50 \%$ (bold line), and $80 \%$ (dotted line) quantiles of the mean areal rainfall for 4-5 May 2002 obtained from 1000 bootstrap samples of 10 radar pixels ("rain gauges") sampled at random (without replication) from $\sim 1600$ pixels, indicating a nearly symmetrical sampling distribution of the mean areal rainfall. Bottom panel: Nearly constant ratio of the $20 \%$ (dashed line), 50\% (dotted line), and $80 \%$ quantiles (solid line) to the "true" mean areal rainfall estimated from all radar pixels.

Tabreux obviously produced an underestimation of the predicted with respect to the measured discharge for the event of 4-10 May 2002 (Fig. 7). The uncertainty affecting the quantitative radar rainfall estimates can have a significant impact on rainfall runoff modelling (e.g. Borga, 2002). A similar analysis for 1-7 March 2003 was impossible because the available radar data covered only one day.

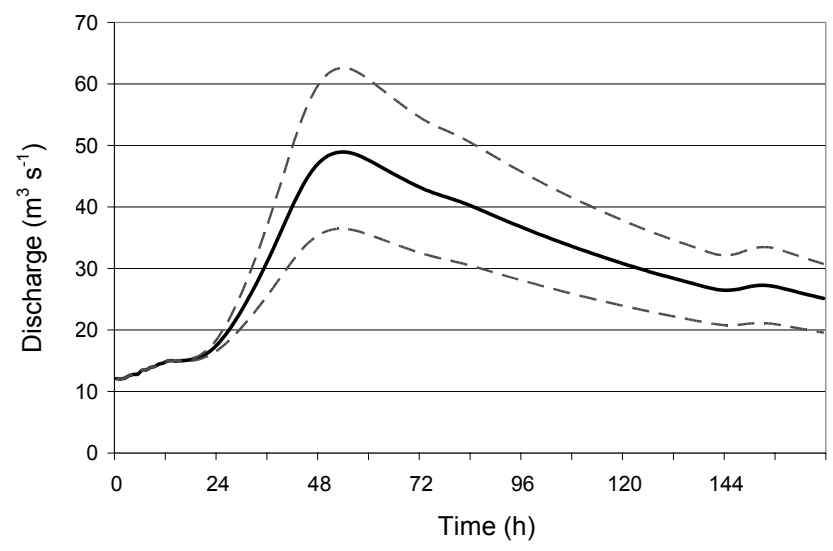

Fig. 9. Uncertainty in the discharge at Tabreux for the period 4-10 May 2002 calculated using the (lumped) HBV-model due to uncertainty in the mean areal rainfall. The solid line indicates the discharge calculated using the mean areal rainfall from the 10 rain gauges (corresponding to the dashed line in Fig. 7), the dashed lines correspond to the discharges calculated using the $20 \%$ and $80 \%$ uncertainty limits (Fig. 8) on the mean areal gauge-derived rainfall over the $1597 \mathrm{~km}^{2}$ catchment area (Fig. 4).

\subsubsection{Quantification of the rain gauge network sampling er- ror}

Recall that HBV is a lumped rainfall-runoff model, in principle not ideal to assess the hydrological impact of spatial rainfall variability. Nevertheless, in this limited setting there is still an interesting application of the power of weather radar, namely its spatial coverage. Approximately $16001 \mathrm{~km} \times 1 \mathrm{~km}$ radar pixels cover the Ourthe basin upstream of Tabreux. Choosing a similar approach as Bradley et al. (2002), one can assume, in a Monte Carlo simulation framework, the radar data to represent the actual rainfall field (1600 "rain gauges") from which a "true" areal average rainfall can be calculated. Also, one can randomly pick (without replication) 10 "gauges" from the 1600 pixels and compute the arithmetic mean of those 10 numbers (obviously, more sophisticated geostatistical interpolation techniques such as Kriging could also be employed to compute this areal average rainfall). This random drawing can be repeated say 1000 times to assess (in a very simple fashion since gauge locations are chosen independently without imposing for instance a minimum inter-gauge distance) the uncertainty in estimating the areal average rainfall over a $1600 \mathrm{~km}^{2}$ catchment from only 10 hourly gauge observations.

To quantify the sampling error affecting the mean areal rainfall derived from the rain gauge network, the $20 \%, 50 \%$ and $80 \%$ quantiles have been determined (see Fig. 8 for an example). In order to associate an uncertainty to the estimated mean areal rainfall, we also calculated the ratios between the quantiles and the "true" mean areal rainfall. These ratios remain remarkably constant as illustrated in Fig. 8 for 4-5 May 2002. Moreover, they are similar for the two studied events (see Table 3). 


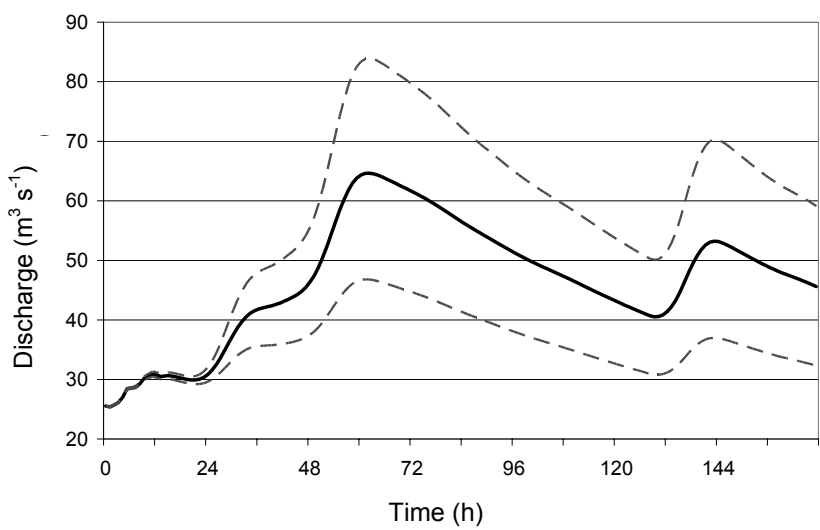

Fig. 10. Same as Fig. 9, but for the period 1-7 March 2003.

The 30-year (1968-1998) HBV run enables us to estimate the standard deviation of the contents of the four model reservoirs (Fig. 6) for every day of the year (Ten Heggeler, 2004). We assume that this standard deviation provides an estimate of the order of magnitude of the uncertainty associated with the initial conditions. It turns out that the hydrological uncertainty associated with the rainfall sampling uncertainty ( $\pm 25 \%$ on an hourly basis for the two events presented, see Figs. 9-10) is of the same order of magnitude as the uncertainty associated with the initial conditions. As an illustration, the sensitivity of the simulated discharge at Tabreux due to an uncertainty of $\pm 5 \mathrm{~mm}$ in the initial content of the fast runoff reservoir (UZ in Fig. 6) is shown in Fig. 11 for the period of 4-10 May 2002 and Fig. 12 for the period of 1-7 March 2003.

\section{Conclusions and recommendations}

The conclusions of this preliminary investigation can be summarized as follows:

- An analysis of the vertical profile of reflectivity for two contrasting rainfall events shows that the stratiform event is characterized by a pronounced maximum just below the zero degree isotherm (the radar "bright band"), wheras the convective event exhibits much more uniform vertical reflectivity profiles. Also, the spatial and temporal variability of the vertical profiles associated with the convective event is much stronger than that associated with the stratiform event.

- An analysis of the apparent vertical reflectivity structure as a function of the distance from the radar (range) shows a smoothing of the profiles at longer ranges and a loss of information at low elevations, which will have an adverse effect on radar-rainfall estimates if left uncorrected.

- The mean areal rainfall over the $\sim 1600 \mathrm{~km}^{2}$ Ourthe catchment upstream of Tabreux estimated from the

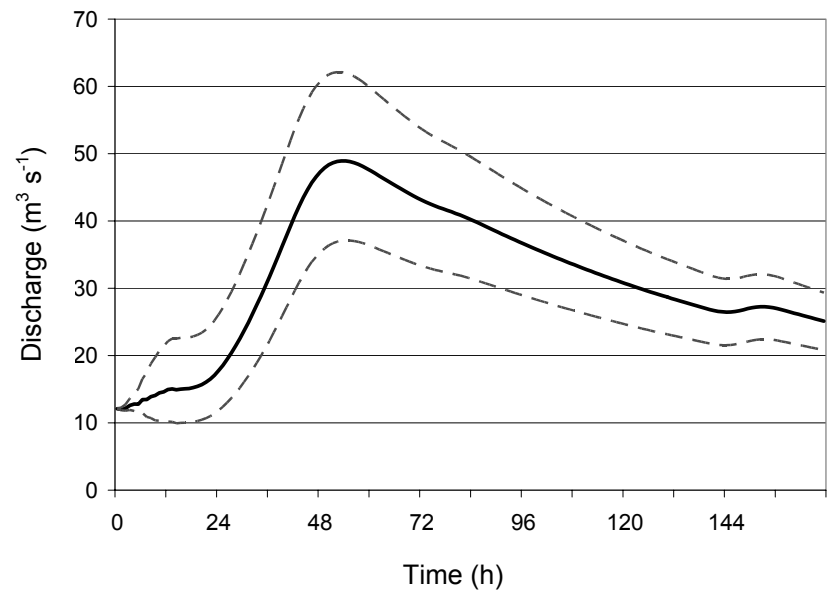

Fig. 11. Sensitivity of the simulated discharge at Tabreux for the period 4-10 May 2002 due to an uncertainty of $\pm 5 \mathrm{~mm}$ in the initial content of the fast runoff reservoir of the HBV model. The solid line indicates the discharge calculated using the mean areal rainfall from the 10 rain gauges (identical to the black line in Fig. 9), the dashed lines correspond to the discharges calculated using a $5 \mathrm{~mm}$ increase and a $5 \mathrm{~mm}$ decrease in the initial content of the fast runoff reservoir (UZ in Fig. 6).

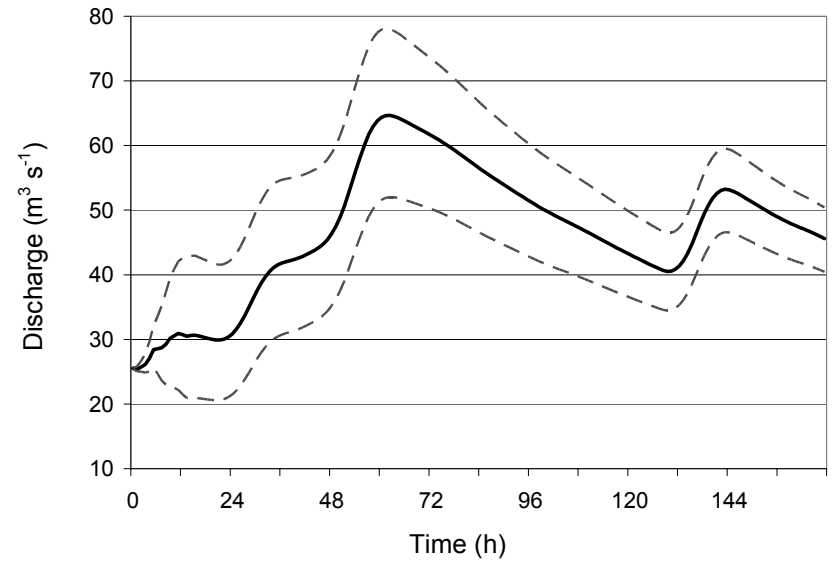

Fig. 12. Same as Fig. 11, but for the period 1-7 March 2003.

Wideumont weather radar using the standard MarshallPalmer reflectivity-rain rate relation (without adjustment to rain gauges) shows biases between $+128 \%$ and $-42 \%$ with respect to the corresponding gauge estimates for six selected precipitation events. For two rainfall events the radar-estimated mean areal rainfall is applied to the gauge-calibrated (lumped) HBV-model for the Ourthe upstream of Tabreux, resulting in a significant underestimation with respect to the observed discharge for one event and a closer match for another.

- The uncertainty in the hourly discharge from the $\sim 1600 \mathrm{~km}^{2}$ Ourthe catchment upstream of Tabreux associated with the sampling uncertainty of the mean areal rainfall estimated from 10 rain gauges evenly spread over the catchment amounts to $\pm 25 \%$ for the two events 
analyzed. This uncertainty is of the same order of magnitude as that associated with the initial conditions.

The development of accurate and robust procedures for correcting for rain-induced attenuation and the vertical profile of reflectivity is the topic of ongoing investigations. It is envisaged that the major floods which occurred during the 20022003 winter season (Fig. 5) will be studied as part of a future collaborative research project. We also foresee a comparison of HBV with runoff estimates from the Hydromax river flow forecasting model, which is currently used operationally at MET-SETHY (see http://www.auto.ucl.ac.be/hydromax/).

Acknowledgements. The first author acknowledges financial support from the European Commission through a Marie Curie Postdoctoral Fellowship (Contract EVK1-CT-2002-50016). The third author acknowledges financial support from the Netherlands Organization for Scientific Research (NWO) through a Vernieuwingsimpuls/VIDI grant (Project 016.021.003). The collaboration between WU, RMI and MET-SETHY is supported by the European Commission as part of Integrated Project FLOODsite (Contract GOCE-CT-2004-505420, see also http://www.floodsite.net/). Finally, we thank M. Borga for his constructive comments.

Edited by: F. Castelli

Reviewed by: M. Borga

\section{References}

Andrieu, H., Creutin, J.-D., Delrieu, G., and Faure, D.: Use of a weather radar for the hydrology of a mountainous area, Part I: Radar measurement interpretation, J. Hydrol., 193, 1-25, 1997.

Berger, H. E. J.: Flow Forecasting for the River Meuse, PhD Thesis, Faculty of Civil Engineering, Delft University of Technology, The Netherlands, 1992.

Berne, A. and Uijlenhoet, R.: Analysis of the influence of the stochastic variability of the raindrop size distribution on radar attenuation correction, Proc. ERAD, 341-346, 2004.

Borga, M.: Accuracy of radar rainfall estimates for streamflow simulation, J. Hydrol., 267, 26-39, 2002.

Bradley, A. A., Peters-Lidard, C., Nelson, B. R., Smith, J. A., and Young, C. B.: Raingage network design using NEXRAD precipitation estimates, J. Amer. Water Resour. As, 38, 5, 1393-1407, 2002

Brandsma, T.: Hydrological Impact of Climate Change, PhD Thesis, Faculty of Civil Engineering, Delft University of Technology, The Netherlands, 1995.

Corral, C., Sempere-Torres, D., Revilla, M., and Berenguer, M.: A semi-distributed hydrological model using rainfall estimates by radar, Application to a Mediterranean basin, Phys. Chem. Earth, 25, 1133-1136, 2000.

Creutin, J.-D., Andrieu, H., and Faure, D.: Use of a weather radar for the hydrology of a mountainous area, Part II: Radar measurement interpretation, J. Hydrol., 193, 26-44, 1997.

De Wit, M. J. M., Warmerdam, P. M. M., Torfs, P. J. J. F., Uijlenhoet, R., Roulin, E., Cheymol, A., Van Deursen, W. P. A., Van Walsum, P. E. V., Ververs, M., Kwadijk, J. C. J., and Buiteveld, H.: Effect of Climate Change on the Hydrology of the River Meuse, Report 104, Hydrology and Quantitative Water Manage- ment Group, Department of Environmental Sciences, Wageningen University, The Netherlands, 2001.

Germann, U.: Radome attenuation - a serious limiting factor for quantitative radar measurements?, Meteorol. Z., 8, 85-90, 1999.

Groot Zwaaftink, M. E.: Hydrological Modeling of the Ourthe, A comparison of Rainfall-Runoff Models, MSc Thesis, Hydrology and Quantitative Water Management Group, Department of Environmental Sciences, Wageningen University, The Netherlands, 2003.

Kwadijk, J. C. J.: The Impact of Climate Change on the Discharge of the River Rhine, PhD Thesis, Department of Physical Geography, Utrecht University, The Netherlands, KNAG/NGS Publication 171, 1993.

Lindström, G., Johansson, B., Persson, M., Gardelin, M., and Bergström, S.: Development and test of the distributed HBV-96 hydrological model, J. Hydrol., 201, 272-288, 1997.

Pfister, L., Humbert, J., and Hoffmann, L.: Recent trends in rainfallrunoff characteristics in the Alzette river basin, Luxembourg, Clim. Change, 45, 323-337, 2000.

RMI: A Weather Radar at Wideumont. Information brochure, Royal Meteorological Institute, Brussels, Belgium (see also http:// www.kmi.be/), 2001.

Sanchez-Diezma, R., Sempere-Torres, D., Delrieu, G., and Zawadzki, I.: Factors affecting the precision of radar measurement of rain. An assessment from an hydrological perspective, Proc. $30^{\text {th }}$ International Conference on Radar Meteorology, American Meteorological Society, Boston, 573-575, 2001.

Sanchez-Diezma, R., Zawadzki, I., and Sempere-Torres, D.: Identification of the bright band through the analysis of volumetric radar data, J. Geophys. Res. - Atm., 105, D, 2225-2236, 2000.

Steiner, M., Houze, R. A., and Yuter, S. E.: Climatological characterization of 3-dimensional storm structure from operational radar and rain-gauge data, J. Appl. Meteorol., 34, 1978-2007, 1995.

Ten Heggeler, M.: Hydrological Modelling and Areal Average Rainfall Estimates of the Ourthe Catchment Derived From the Wideumont Weather Radar and Precipitation Gauges, MSc Thesis, Hydrology and Quantitative Water Management Group, Department of Environmental Sciences, Wageningen University, The Netherlands, 2004.

Uijlenhoet, R., De Wit, M. J. M., Warmerdam, P. M. M., and Torfs, P. J. J. F.: Statistical Analysis of Discharge Data of the River Meuse and its Tributaries (1968-1998): Assessment of Drought Sensitivity, Report 100, Hydrology and Quantitative Water Management Group, Department of Environmental Sciences, Wageningen University, The Netherlands, 2001.

Van den Hurk, B.: Development of a European Land Data Assimilation System to Predict Floods and Droughts (ELDAS), Description of Work of EU RTD Project EVG1-CT-2001-00050, 2001.

Velner, R. G. J.: Rainfall-runoff Modeling of the Ourthe Catchment Using the HBV Model - A Study Towards Increasing the Leadtime of Flood Forecasts on the River Meuse, MSc Thesis, Hydrology and Quantitative Water Management Group, Department of Environmental Sciences, Wageningen University, The Netherlands, 2000.

Wójcik, R. and Buishand, T. A.: Simulation of 6-hourly rainfall and temperature by two resampling schemes, J. Hydrol., 273, 69-80, 2003. 